\title{
THE SECONDARY CHARACTERISTIC FLUORESCENCE CORRECTION IN THE EPMA
}

\author{
I.M. Anderson,* C.B. Carter, $\dagger$ and J. Bentley*
}

*Metals \& Ceramics Division, Oak Ridge National Laboratory, P.O. Box 2008, Oak Ridge, TN 37831-6376

$\lceil$ Department of Chemical Engineering \& Materials Science, University of Minnesota, Minneapolis, MN 55455

A recent approach to secondary fluorescence correction combines the many factors that enter a correction formula into a few readily interpretable factors. ${ }^{1}$ The strength of this approach is that it gives an intuitive appreciation of the extent of secondary fluorescence in any microanalysis situation. The fluoresced intensity, $I_{Y}^{Y}$, of an element $X$ by an element $Y$ is expressed relative to the primary intensity, $I_{Y}$, of the fluorescing element as:

$I_{X}^{Y} / I_{Y}=C^{Y} X * P X \Omega_{e f f}\left(m{ }^{Y}\right) / 4 \pi$.

The simplicity of equation (1) follows directly from expressing the fluoresced intensity, ${ }^{Y} Y_{X}$, as a fraction of the primary intensity of the fluorescing element, IY, rather than the primary intensity of the fluoresced element, IX. This form of correction formula is necessary when the composition of the fluoresced volume of the specimen differs from that of the probed volume. This situation is usual for electron-transparent specimens analyzed in the analytical electron microscope (AEM), which are rarely homogeneous on the scale $(\sim 10 \mu \mathrm{m})$ over which the primary $\mathrm{x}$ rays are absorbed. ${ }^{1}$ The $I_{\mathrm{Y}} \mathrm{Y}_{\mathrm{X}} / \mathrm{I}_{Y}$ form of the correction has also been adopted by investigators studying inhomogeneous specimens in the electron probe microanalyzer (EPMA), such as when the analyzed volume is in the vicinity of a lateral or vertical interface. 2,3

For a given material, the factors $C^{Y} X$ and $P X$ are fixed. $C^{Y} X$ gives the compositional dependence of the secondary fluorescence correction; it is equal to zero when element $\mathrm{X}$ is absent from the fluoresced volume and equal to unity when the fluoresced volume is composed entirely of element $\mathrm{X}$. $\mathrm{PX}$ gives the $\mathrm{X}$-ray fluorescence probability of the fluoresced element $X$; it is dominated by the fluorescent yield $\omega X$. The factor $\Omega_{\text {eff }}(\mathrm{m} Y \mathrm{X}) / 4 \pi$ gives the dependence of the correction on specimen geometry. The parameter $\mathrm{m}^{\mathrm{Y}} \mathrm{X}$ is the secondary fluorescence absorption parameter, denoted $x$ in the formulations of Castaing and Reed, 4,5 or $u$ in the text by Goldstein et al., 6 and is analogous to the absorption parameter $\chi$ for absorption correction. It has been shown that when absorption of fluoresced $x$ rays in the specimen vanishes $\left(\mathrm{m}^{Y} \mathrm{X}=0\right)$, the geometric factor is simply the fractional solid angle subtended by the fluoresced volume, denoted $\Omega_{F} / 4 \pi{ }^{1}$ For example, for a standard EPMA specimen analyzed such that the primary $x$-ray intensity distribution is concentrated at the entrance surface, as would result from a low overvoltage ratio for the fluorescing element $\mathrm{Y}, \Omega_{\mathrm{eff}}\left(\mathrm{m}_{\mathrm{Y}} \mathrm{X}\right) / 4 \pi=\ln \left(1+\mathrm{m} \mathrm{Y}_{\mathrm{X}}\right) / 2 \mathrm{~m}_{\mathrm{X}}$ and $\Omega_{4} / 4 \pi=1 / 2$. The latter factor indicates that the specimen subtends half of the fractional solid angle surrounding the analyzed volume (the semi-infinite slab below the surface); the former dependence is well known.

Geometric factors have been derived for the traditional EPMA specimen geometry. ${ }^{7}$ A closed-form expression for the geometric factor can be derived if a relatively simple $\phi(\rho z)$ dependence is assumed. If the simple exponential (Lenard) dependence is used, the geometric factor is:

$\Omega_{e f f}\left(m_{X}\right) / 4 \pi=\frac{1}{2} \frac{n Y_{e}}{n^{Y_{e}}+m_{X} Y_{X}}\left\{\frac{\ln \left(1+m^{Y} X\right)}{m Y_{X}}+\frac{\ln \left(1+n^{Y_{e}}\right)}{n_{e}}\right\}$.

Here, $\mathrm{n}_{\mathrm{e}}$ is a nomalized Lenard electron absorption coefficient, equivalent to the parameter $y$ in the CastaingReed formulation 4,5 or the parameter $v$ in the notation of Goldstein et al. 6 The geometric factor in equation (2) is that derived by Castaing but with an additional factor of $\mathrm{nY}_{\mathrm{e}} /\left(\mathrm{n}_{\mathrm{e}}+\mathrm{m}_{\mathrm{Y}} \mathrm{X}\right)$. This discrepancy arises because Castaing neglected the absorption of fluoresced $x$ rays in the layer between the primary $x$-ray excitation event and the specimen surface. ${ }^{4}$ The effect of such absorption is relatively mild since the penetration of the incident electrons into the specimen is small relative to the penetration of primary $x$ rays. However, the neglect of this factor, which is equivalent to a factor of $y /(x+y)$ in the notation of Castaing and Reed or $v /(u+v)$ in Goldstein et al., can lead to a measurable systematic error at high overvoltage ratios: $\sim 0.2 \%$ in the calculated chromium concentration $\mathrm{C}_{\mathrm{Cr}}$ of strongly fluorescing $\mathrm{Fe}-10 \% \mathrm{Cr}$ analyzed at an accelerating potential of $30 \mathrm{kV} .{ }^{7}$ This error is avoided if the additional factor in equation (2) is appended to the secondary fluorescence correction formula. The fluorescence correction is relatively weakly dependent on $\phi(\rho z)$; the more realistic Packwood-Brown dependence 8 yields the same calculated $\mathrm{Cr}$ intensity in $\mathrm{Fe}-10 \% \mathrm{Cr}$ as equation (2) to within $-0.03 \%$ at $30 \mathrm{kV}$. This relative insensitivity of secondary fluorescence to $\phi(\rho z)$ is not unique to the traditional EPMA specimen geometry: it has also been explicitly demonstrated for spherical particles and parallel-sided thin foils. 9,10

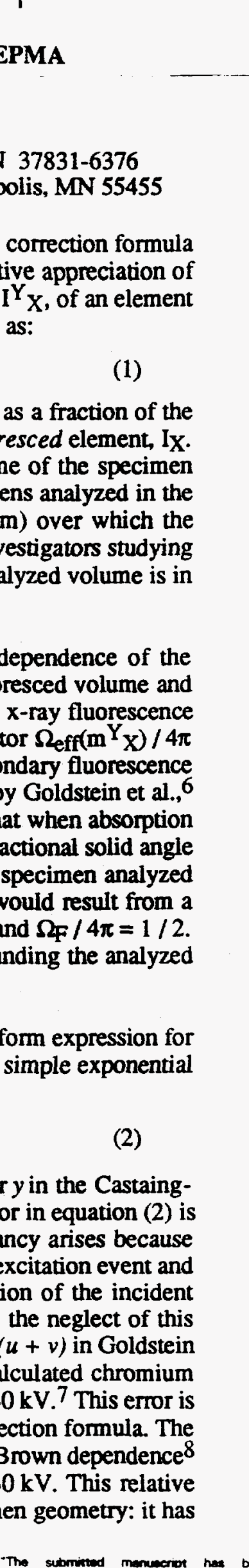

The subminud manucriot has been authored by contrector of the U.S. ACO5-84OA2 1400. Accordingty. the U.S rovernment reters a norexchesve the publighed form of this contribution. or silow others to oo so. for U.S. Government 
The factor $\Omega_{F} / 4 \pi$ can be calculated by setting $m^{Y} X=0$ :

$\Omega_{\mathrm{F}} / 4 \pi=\frac{1}{2}\left\{1+\frac{\ln \left(1+\mathrm{n}_{\mathrm{e}}\right)}{\mathrm{n} \mathrm{Y}_{\mathrm{e}}}\right\}$.

The interpretation of this factor as the fractional solid angle subtended by the fluoresced volume (here, the specimen) from the perspective of the analyzed volume can be examined by evaluating this factor in two different limits. If $\mathrm{n}_{\mathrm{e}} \rightarrow \infty$, the second factor in braces in equation (3) tends to zero, so that $\Omega_{\mathrm{F}} / 4 \pi=1 / 2$. Physically, this limit corresponds to an infinite Lenard coefficient, so that all of the incident electrons are absorbed at the specimen surface, as shown schematically in Fig. 1a. The volume over which primary $x$ rays are absorbed is indicated. In agreement with the proposed interpretation, the specimen subtends half of the fractional solid angle surrounding the analyzed volume - the semi-infinite plane below the specimen surface. Conversely, if $\mathrm{n}_{\mathrm{e}} \rightarrow 0$, the second factor in braces in equation (3) tends to unity, so that $\Omega_{F} / 4 \pi=1$. This limit corresponds to a negligible Lenard coefficient so that the electron penetration into the specimen far exceeds the distance over which primary $x$ rays are absorbed, as represented schematically in Fig. 1b. Here, as expected, the specimen completely surrounds the "analyzed volume". This intuitive understanding of the influence of specimen geometry on secondary fluorescence can be used to estimate the fluorescence for many microanalysis geometries. ${ }^{1 P}$

\section{References}

1. I.M. Anderson, J. Bentley, and C.B. Carter, J. Microsc. (1995) in press.

2. F. Glas, in Analytical Electron Microscopy, London: Inst. of Metals (1988)27.

3. J.-L. Pouchou and F. Pichoir, in K.F.J. Heinrich and D.E. Newbury, Eds., Electron Probe Quantitation, New York: Plenum Press (1991)71.

4. R. Castaing, PhD thesis, University of Paris, translated by P. Duwez and D.B. Wittry (1951)120ff.

5. S.J.B. Reed, Brit. J. Appl. Phys. 16(1965)913.

6. J.I. Goldstein et al., Scanning Electron Microscopy and X-ray Microanalysis, Second ed., New York: Plenum Press (1992)430.

7. I.M. Anderson, J. Bentley, and C.B. Carter, in preparation.

8. $\quad$ R.H. Packwood and J.D. Brown, X-ray Spectrom. 10(1981)138.

9. J.T. Armstrong and P.R. Buseck, X-ray Spectrom. 14(1985)172.

10. C.E. Nockolds, in D.C. Joy, Ed., Analytical Electron Microscopy - 1987, San Francisco: San Francisco Press (1987)221.

11. This research was supported by the Division of Materials Sciences, U.S. Department of Energy, through the SHaRE Program under contract DE-AC05-760R00033 with Oak Ridge Associated Universities and under contract DE-AC05-84OR21400 with Martin Marietta Energy Systems, Inc., and by the National Science Foundation under grant DMR-8901218. This work was also partially supported by an appointment (IMA) to the Oak Ridge National Laboratory Postdoctoral Research Associates Program, which is administered jointly by the Oak Ridge Institute for Science and Education and Oak Ridge National Laboratory.

a

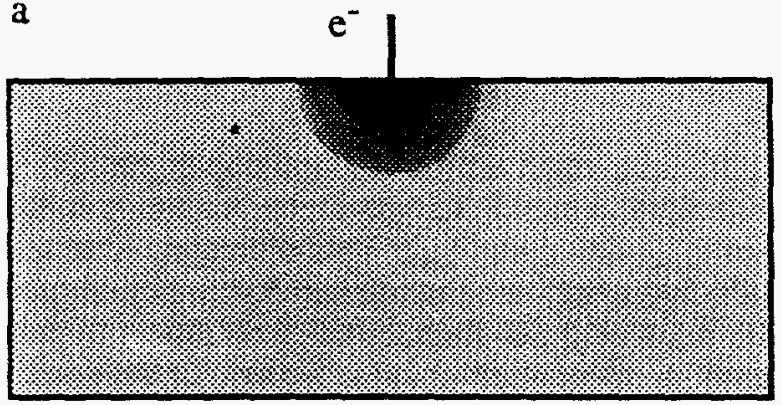

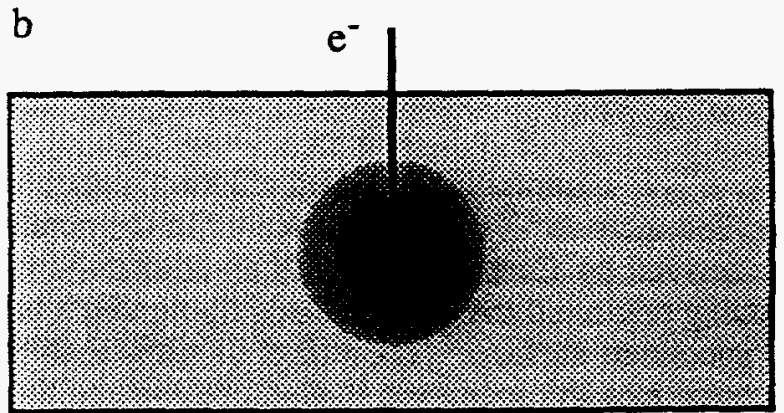

FIG. 1. Schematic representation of secondary fluorescence in the EPMA for $\mathrm{n} \mathrm{Y}_{\mathrm{e}} \rightarrow$ (a) $\infty$ and (b) 0 . In (a) the specimen subtends only half of the fractional solid angle surrounding the analyzed volume $\left(\Omega_{F} / 4 \pi=1 / 2\right)$ whereas in (b) the specimen surrounds the entire analyzed volume $\left(\Omega_{F} / 4 \pi=1\right)$. 


\section{DISCLAIMER}

This report was prepared as an account of work sponsored by an agency of the United States Government. Neither the United States Government nor any agency thereof, nor any of their employees, makes any warranty, express or implied, or assumes any legal liability or responsibility for the accuracy, completeness, or usefulness of any information, apparatus, product, or process disclosed, or represents that its use would not infringe privately owned rights. Reference herein to any specific commercial product, process, or service by trade name, trademark, manufacturer, or otherwise does not necessarily constitute or imply its endorsement, recommendation, or favoring by the United States Government or any agency thereof. The views and opinions of authors expressed herein do not necessarily state or reflect those of the United States Government or any agency thereof.

This report has been reproduced directly from the best available copy.

Available to DOE and DOE contractors from the Office of Scientific and Technical Information, 175 Oak Ridge Turnpike, Oak Ridge, TN 37831; prices available at (615) 576-8401.

Available to the public from the National Technical Information Service, U.S. Department of Commerce, 5285 Port Royal Road, Springfield, VA 22161; phone orders accepted at (703) 487-4650. 


\section{DISCLAIMER}

Portions of this document may be illegible in electronic image products. Images are produced from the best available original document. 